\title{
Basal Cell Carcinoma Arising from a Follicular Hybrid Cyst
}

\author{
Takayuki Aizu, Takahide Kaneko, Noriko Takiyoshi, Satoko Minakawa, Ayumi Korekawa, \\ Hajime Nakano, Daisuke Sawamura* \\ Department of Dermatology, Hirosaki University Graduate School of Medicine, Hirosaki, Japan \\ Email: ${ }^{\text {derma@hirosaki-u.ac.jp }}$
}

Received 4 August 2015; accepted 20 September 2015; published 23 September 2015

Copyright @ 2015 by authors and Scientific Research Publishing Inc.

This work is licensed under the Creative Commons Attribution International License (CC BY). http://creativecommons.org/licenses/by/4.0/

(c) (i) Open Access

\begin{abstract}
Malignant tumors arising from follicular cysts are rare. Herein, we report of a 62-year-old Japanese woman with a slowly growing tumor, $22 \times 20 \mathrm{~mm}$ in size, located on her nose for 2 years. Histopathological examination of the surgically excised tumor showed that the tumor cells were basaloid and formed peripheral palisading patterns. The tumor contained a cystic structure in its center, and the cyst wall was lined with stratified epithelium with or without keratohyalin granules. Based on these findings, a diagnosis of basal cell carcinoma arising from a follicular hybrid cyst was made. To our knowledge, this is the first case of basal cell carcinoma originating from a follicular hybrid cyst. A review of previous reports of basal cell carcinoma from a follicular cyst indicated that the majority of previous cysts were located on the face, and that the lesions had been present for a relatively long time. The present case showed typical clinical findings and followed a regular course. Malignant transformation may be a rare event, but it can occur in a follicular cyst, so cysts and suspected cysts, especially those found on the face and those persisting for relatively long time, should always be subjected to histological examination.
\end{abstract}

\section{Keywords}

Epidermoid Cysts, Trichilemmal Cyst, Malignant Transformation

\section{Introduction}

There are two types of follicular cysts: epidermoid and trichilemmal. Epidermoid cysts produce keratohyalin, which forms a horny material resembling the epidermis. Trichilemmal cysts are characterized by abrupt keratinization without keratohyalin granules. Furthermore, there are hybrid cysts, which are combinatory keratinous

\footnotetext{
${ }^{*}$ Corresponding author.
}

How to cite this paper: Aizu, T., Kaneko, T., Takiyoshi, N., Minakawa, S., Korekawa, A., Nakano, H. and Sawamura, D. (2015) Basal Cell Carcinoma Arising from a Follicular Hybrid Cyst. Case Reports in Clinical Medicine, 4, 317-320. 
cysts with both epidermoid and trichilemmal zones that are separated by an abrupt transition [1]. Malignant tumors arising from follicular cysts are rare. Herein, we report a case of basal cell carcinoma arising from a follicular hybrid cyst of the skin.

\section{Case Report}

A 62-year-old Japanese woman with a slowly growing tumor on her nose for 2 years was referred to our department for evaluation. Physical examination revealed an erythematous, irregularly pigmented, $22-\times 20-\mathrm{mm}$ dermal tumor on the left dorsum of her nose (Figure 1(a)). Dermoscopy of the tumor showed multiple blue-gray ovoid nests and arborizing vessels (Figure 1(b)), and ultrasonography of the tumor demonstrated a low echoic area indicating a cystic structure (Figure 1(c)).

With a provisional diagnosis of basal cell carcinoma, a punch biopsy was performed under local anesthesia. The specimen showed various-sized islands of uniform basaloid cells showing peripheral palisading patterns (Figure 2(a)); diagnosis was confirmed as basal cell carcinoma.

Surgical excision of the tumor was performed. Histopathological examination showed that the whole tumor extended from the upper dermis to the subcutaneous tissue (Figure 2(b)). The tumor cells were basaloid and formed peripheral palisading patterns. The tumor contained a cystic structure in its center and the tumor cell nests were not separated from their associated stroma. The cyst wall was lined with stratified epithelium with or without keratohyalin granules (Figure 2(c) and Figure 2(d)). A portion of the wall was replaced by basaloid cells without stratified epithelium. Immunohistochemical staining showed that the tumor cells were positive for Ber-EP4. Based on these findings, basal cell carcinoma arising in a follicular hybrid cyst was diagnosed.

\section{Discussion}

Cysts of the skin are very common, and the most frequent cutaneous cysts are follicular cysts, the walls of which are lined by stratified squamous epithelia. There are two types of follicular cysts: epidermoid and trichilemmal. Epidermoid cysts are lined by a keratinized epithelium with a distinct granular layer, and the site of origin is thought to be the infundibular portion of the hair follicle. On the other hand, trichilemmal cysts originate from the outer hair root sheath. The wall of the cyst consists of stratified squamous epithelium that has a palisaded outer layer, and the inner layer does not have a granular layer. The hybrid cyst is a combination of epidermoid and trichilemmal cysts [1].

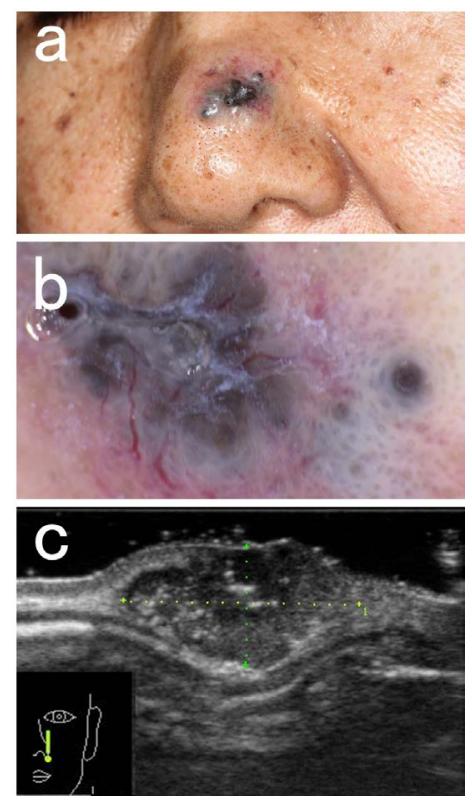

Figure 1. Clinical, dermoscopic, and ultrasonographic findings. (a) An irregularly pigmented erythematous dermal tumor on the left dorsum of the nose, $22 \times 20 \mathrm{~mm}$ in size; (b) Dermoscopy showed multiple blue-gray ovoid nests and arborizing vessels; (c) Ultrasonography demonstrated low echoic area in the center of the tumor indicating a cystic structure. 


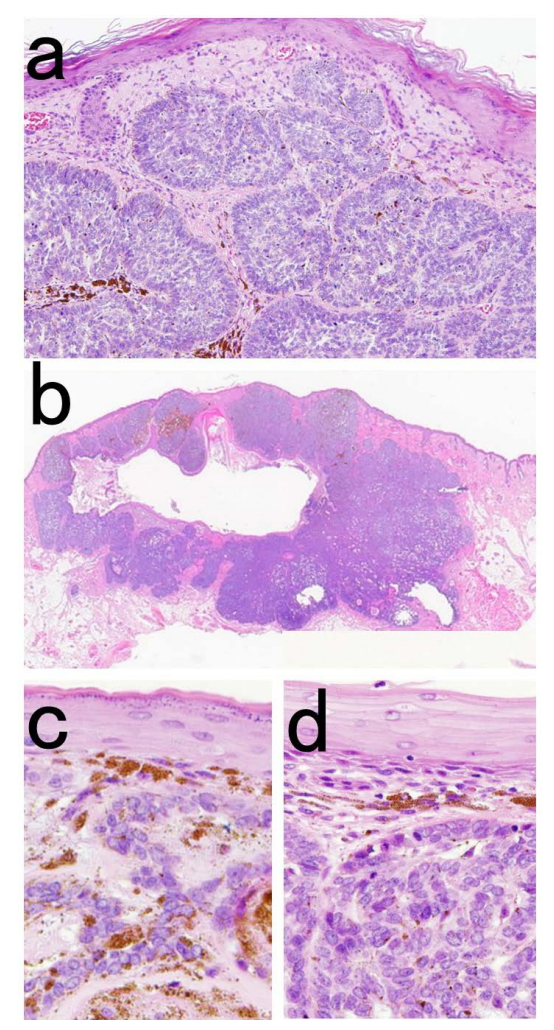

Figure 2. Histological findings. (a) The biopsy specimen showed various-sized islands of uniform basaloid cells showing peripheral palisading patterns. HE staining, 40×. (b) The whole tumor encompassed the region from the upper dermis to the subcutaneous tissue. The tumor cells were basaloid and formed peripheral palisading patterns. The tumor consisted of a cystic structure in its center; the tumor cell nests were not separated from their associated stroma. HE staining, 4×. (c) and (d) The cyst wall was lined with stratified epithelium with (c) or without (d) keratohyalin granules. HE staing, 200×.

Malignant tumors arising from follicular cysts are rare. Cameron and Hilsinger reported that only one squamous cell carcinoma was found among 2246 cases of epidermoid cysts, and there were no cases of basal cell carcinoma [2]. Delacretaz reviewed malignant tumors arising from follicular cysts and added a case of his own [3]. Among these cases, 51 were squamous cell carcinomas, 18 were basal cell carcinomas, 3 were basosquamous cell carcinomas, and the remaining 5 were not specified. Focusing on basal cell carcinoma cases arising from follicular cysts, 8 were from an epidermoid cyst and 3 were from a trichilemmal cyst, and in the remaining 7 cases, the cyst types were not specified. Tsujita-Kyotoku et al. reviewed 13 Japanese cases of basal cell carcinoma from follicular cysts [4]. Clinically, most of the cysts were located on the face and ranged from 0.7 to $6.0 \mathrm{~cm}$ in diameter. The lesions had been present for a relatively long time, ranging from 1.5 months to 56 years. The present case was observed in a 62-year-old woman; her tumor was $22 \times 20 \mathrm{~mm}$ in size, and it had been growing slowly for 2 years on her nose. Thus, the present case showed typical clinical findings and followed a typical course. Also, there was two cases of basal cell carcinoma from epidermoid cyst form Japan [5] [6]. Tsujita-Kyotoku et al. also determined that basal cell caricinoma was shown to arise histologically from an epidermoid cyst in 8 patients, from a trichilemmal cyst in 3, and from an atheroma (unknown) in 2 [4]; there was no hybrid cyst in the 13 previously described cases. As far as we know, there are no previous reports of basal cell carcinoma originating from a follicular hybrid cyst.

Basal cell carcinoma is the most common malignant tumor in the dermatological field. However, squamous cell carcinoma is the most common among malignant tumors arising from a follicular cyst [3]. Sun exposure is the most important environmental cause of basal cell carcinoma. Much less ultraviolet right reaches a follicular cyst than other sun-exposed areas; this may explain the inversion of the frequencies of basal and squamous cell carcinomas in follicular cysts.

Follicular cysts are extremely common skin tumors; as a result, their excision and histological examination is sometimes omitted in clinical practice. Malignant transformation may be a rare event, but it can definitely occur 
in follicular cysts, so cysts and suspected cysts, especially those occurring on the face and those persisting for a relatively long time, should always be subjected to histological examination.

\section{References}

[1] Brownstein, M.H. (1983) Hybrid Cyst: A Combined Epidermoid and Trichilemmal Cyst. Journal of the American Academy of Dermatology, 9, 872-875. http://www.ncbi.nlm.nih.gov/pubmed/6643785 http://dx.doi.org/10.1016/s0190-9622(83)70201-x

[2] Cameron, D.S. and Hilsinger Jr., R.L. (2003) Squamous Cell Carcinoma in an Epidermal Inclusion Cyst: Case Report. Otolaryngology—Head and Neck Surgery, 129, 141-143. http://dx.doi.org/10.1016/S0194-5998(03)00466-2

[3] Delacrétaz, J. (1977) Keratotic Basal-Cell Carcinoma Arising from an Epidermoid Cyst. The Journal of Dermatologic Surgery and Oncology, 3, 310-311. http://dx.doi.org/10.1111/j.1524-4725.1977.tb00299.x

[4] Tsujita-Kyutoku, M., Danbara, N., Yuri, T., Nikaido, Y., Hatano, T. and Tsubura, A. (2005) Basal Cell Carcinoma Arising from a Keratinous Cyst of the Skin: A Case Report and Review of the Literature. Medical Molecular Morphology, 38, 130-133. http://dx.doi.org/10.1007/s00795-004-0285-9

[5] Ikeda, I. and Ono, T. (1990) Basal Cell Carcinoma Originating from an Epidermoid Cyst. The Journal of Dermatology, 17, 643-646. http://www.ncbi.nlm.nih.gov/pubmed/2273167 http://dx.doi.org/10.1111/j.1346-8138.1990.tb01709.x

[6] Tanaka, M., Terui, T., Sasai, S. and Tagami, H. (2003) Basal Cell Carcinoma Showing Connections with Epidermal Cysts. Journal of the European Academy of Dermatology and Venereology, 17, 581-582. http://www.ncbi.nlm.nih.gov/pubmed/12941101 http://dx.doi.org/10.1046/j.1468-3083.2003.00807.x 